Article

\title{
Simulation Analysis of China's Energy and Industrial Structure Adjustment Potential to Achieve a Low-carbon Economy by 2020
}

\section{Nan Xiang ${ }^{1,2,3}$, Feng $X u^{4, *}$ and Jinghua Sha ${ }^{1,3, *}$}

1 School of Humanities and Economic Management, China University of Geosciences, Beijing 100083, China; E-Mail: nancyxiang86@hotmail.com

2 Graduate School of Management, University of Chinese Academy of Sciences, Beijing 100190, China

3 Key Laboratory of Carrying Capacity Assessment for Resource and Environment, Ministry of Land and Resource, Beijing 100083, China

4 School of Environment Sciences, Tsinghua University, Beijing 100084, China

* Authors to whom correspondence should be addressed; E-Mails: xufeng_t@tsinghua.edu.cn (F.X.); shajinghua@163.com (J.S.); Tel.: +86-10-6279-4904 (F.X.); +86-10-8232-2078 (J.S.).

Received: 14 October 2013; in revised form: 21 November 2013 / Accepted: 22 November 2013 / Published: 28 November 2013

Abstract: To achieve a low-carbon economy, China has committed to reducing its carbon dioxide $\left(\mathrm{CO}_{2}\right)$ emissions per unit of gross domestic product (GDP) by $40 \%-45 \%$ by 2020 from 2005 levels and increasing the share of non-fossil fuels in primary energy consumption to approximately $15 \%$. It is necessary to investigate whether this plan is suitable and how this target may be reached. This paper verifies the feasibility of achieving the $\mathrm{CO}_{2}$ emission targets by energy and industrial structure adjustments, and proposes applicable measures for further sustainable development by 2020 through comprehensive simulation. The simulation model comprises three sub-models: an energy flow balance model, a $\mathrm{CO}_{2}$ emission model, and a socio-economic model. The model is constructed based on input-output table and three balances (material, value, and energy flow balance), and it is written in LINGO, a linear dynamic programming language. The simulation results suggest that China's carbon intensity reduction promise can be realized and even surpassed to $50 \%$ and that economic development (annual 10\% GDP growth rate) can be achieved if energy and industrial structure are adjusted properly by 2020 . However, the total amount of $\mathrm{CO}_{2}$ emission will reach a relatively high level-13.68 billion tons-which calls for further sound approaches to realize a low carbon economy, such as energy utilization efficiency improvement, technology innovation, and non-fossil energy's utilization. 
Keywords: low-carbon economy; energy balance; industrial structure; dynamic simulation

\section{Introduction}

Between 1979 and 2007, the Chinese economy grew at an average annual rate of 9.8\% [1]. As economic growth has increased, environmental pollution problems have become serious in places where social and political stability are at risk [2]. By 2005, China's $\mathrm{CO}_{2}$ emission caught up with and surpassed that of the United States in five years rather than the 15-20 years projected by most forecasts published as late as 2004 [3]. With a large population, rapidly expanding economy, and heavy reliance on coal, China's $\mathrm{CO}_{2}$ emissions are expected to continue growing in the years ahead.

$\mathrm{CO}_{2}$ emission is a worldwide problem, and solving this environmental problem in China will be expensive. According to an estimation, the cost of outdoor air and water pollution to China's economy totaled approximately $5.8 \%$ of China's GDP [4]. Accordingly, the Chinese government gave a high priority to environmental protection, particularly to reducing the $\mathrm{CO}_{2}$ emission to alleviate the environment risks for China and the rest of the world. China said it would do its best to reduce its $\mathrm{CO}_{2}$ emissions per unit of GDP by 40\%-45\% from the 2005 levels by 2020 and increase the share of non-fossil fuels in primary energy consumption to approximately 15\% [5]. The targets that China has set are of major consequence and, if met, will make a significant contribution to international mitigation efforts.

China is expending great effort to become a so-called low-carbon society, which refers to low carbon emissions with a high quality of life and suitable economic development [6]. China will face great challenges in implementing these policies. Although the national intensity reduction target is clearly set, how this target should be allocated to the various sectors has not yet been determined [7].

There is a great deal of research focused on the Chinese government's ambitious goal, particularly with regard to $\mathrm{CO}_{2}$ emission forecasts for 2020. Some have estimated the $\mathrm{CO}_{2}$ emission using sector studies, energy structure analysis, regional distribution, etc. to find the optimal approach to the Chinese targets. This paper aims to investigate verifies the feasibility of achieving the $\mathrm{CO}_{2}$ emission targets by energy and industrial structure adjustments, and proposes applicable measures for further sustainable development by 2020 through comprehensive simulation.

Proper and reliable forecasting of the $\mathrm{CO}_{2}$ emission and socio-economic development should be based on a comprehensive system with thorough consideration of the current situation. We will introduce the current $\mathrm{CO}_{2}$ emission situation in China in the following section.

\subsection{Overview of China's Energy Structure}

China's energy production is increasing significantly along with high-speed economic development (Figure 1). In 2010, the total amount of energy production in China was 2969 million tons of standard coal equivalents (TCE). Among the four types of energy resources, coal still occupied the largest part of the energy supply, approximately $76.5 \%$ in 2010 . The proportion of non-fossil energy in energy production increased yearly from $7.5 \%-9.4 \%$ in $2006-2010$. Along with encouraging clean energy utilization in China, the proportion of non-fossil energy will be further increased. 
Figure 1. The total amount of energy production and structure trends from 2006-2010 in China [8].

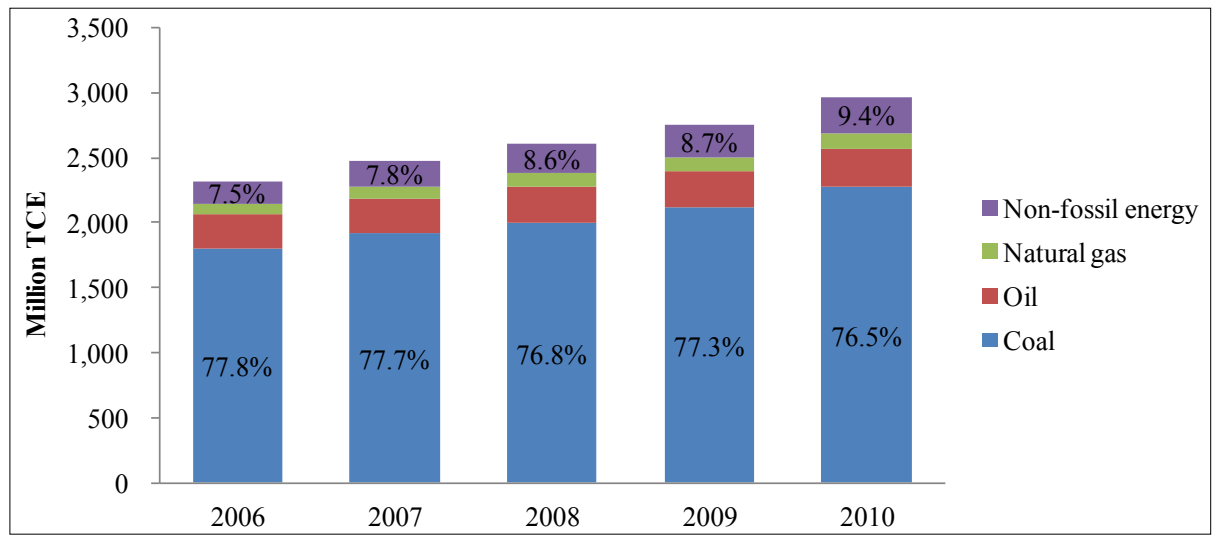

The total amount of energy consumed in 2010 was 3249 million TCE, as shown in Figure 2. Coal was the most important energy resource [9], representing approximately $68 \%$ of the total primary energy use, with the remainder being oil and, to a much lesser extent, non-fossil energy and natural gas. The proportion of oil supply is increased significantly due to large oil imports. Additionally, Figure 2 illustrates that the ratio of non-fossil energy to the total energy supply has constantly increased. There was 280 million TCE's energy imported from abroad, accounting for 9\% of the 2010 total energy consumption. Imported energy, mainly oil, contributed significantly to China's energy consumption. Because it is largely dependent on imported oil, China's energy consumption structure faces supply risks in the world market.

Figure 2. The total amount of energy consumed and structure trends from 2006-2010 in China [8].

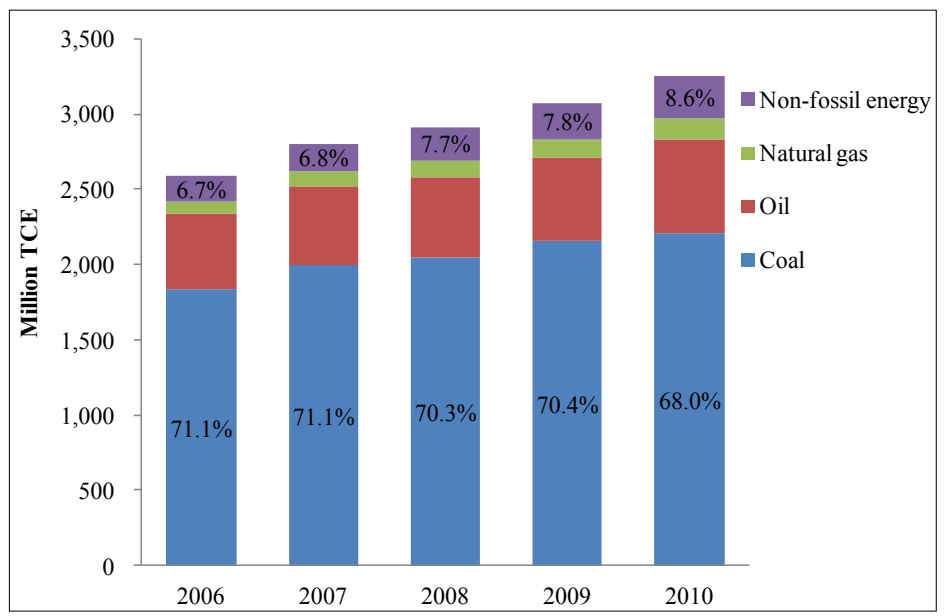

Large pollution problems, especially greenhouse gases (GHG) (including $\mathrm{CO}_{2}, \mathrm{CH}_{4}, \mathrm{~N}_{2} \mathrm{O}$ ), are related to coal use. Non-fossil energy cannot only improve the energy structure's stability but also reduce GHG gas emissions. An energy supply and demand structure shift from coal to clean energy can reduce $\mathrm{CO}_{2}$ emissions significantly. Therefore, the Chinese government proposed lots of plans to prompt non-fossil energy utilization in the coming years. 


\subsection{Overview of China's Industrial Structure Changes}

China's GDP increased from 20,631 billion CNY to 39,798 billion CNY with an annual rate of increase of $11.22 \%$ from 2006-2010 (Figure 3), and the industrial structure changed significantly in this period. In 2010 , the proportion of tertiary industry was $43.1 \%$, while primary industry was $10.1 \%$, and secondary industry was $46.8 \%$.

Figure 3. China's industrial production from 2006-2010 [8].

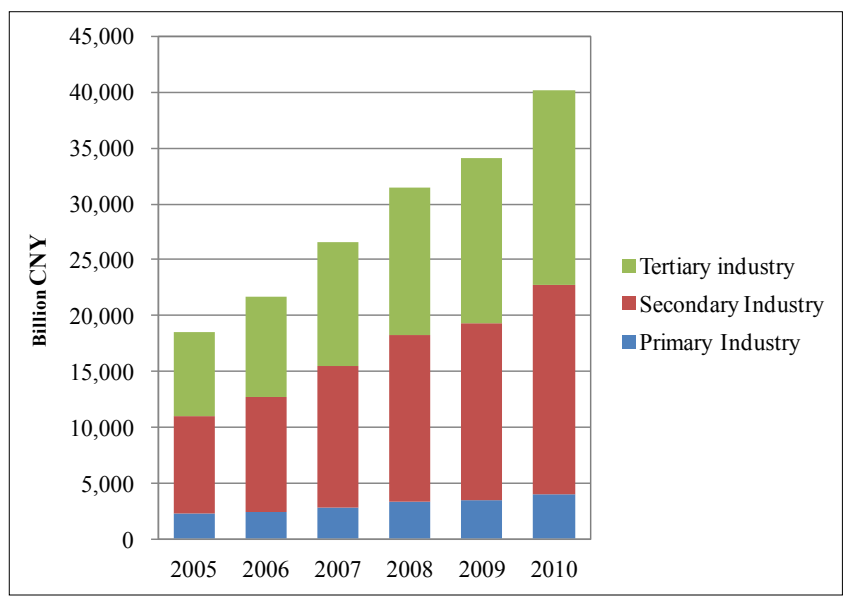

In 2010, Chinese energy consumption is 3249 million TCE in total. Figure 4 demonstrates that secondary industry was the major energy consumer in China, constituting $71 \%$ of the total energy consumption. Tertiary industry only consumed approximately $16 \%$ of the total energy, while its product was nearly equal to that of secondary industry. Secondary industry had greater energy consumption and higher $\mathrm{CO}_{2}$ emission than other industries. A higher growth rate, especially if accompanied by a more rapid shift to higher value manufacturing and services, would help achieve China's carbon intensity target.

Figure 4. The energy consumption structure and amount in China in 2010 [8].

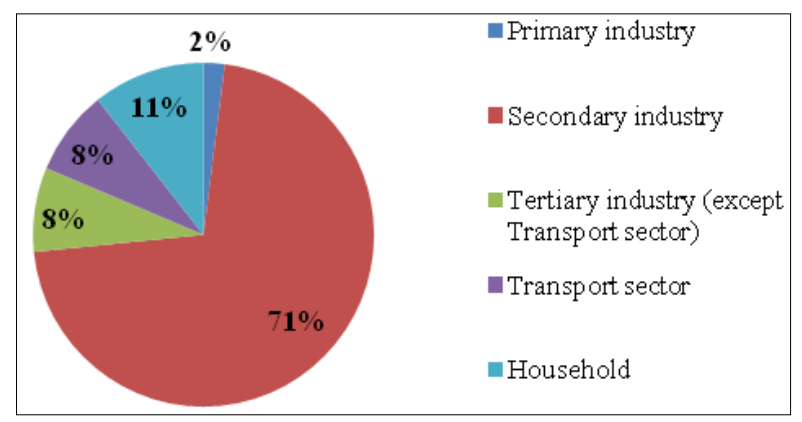

\subsection{Overview of China's $\mathrm{CO}_{2}$ Emission}

As shown in Figure 5, China became the highest $\mathrm{CO}_{2}$-emitting country in 2005 according to the World Bank database [10]. Additionally, $\mathrm{CO}_{2}$ emissions reached 7031 million tons in 2008, which is much higher than expected described in various studies. Furthermore, the total $\mathrm{CO}_{2}$ generation is not declining observed from the $\mathrm{CO}_{2}$-emitting trend. 
Figure 6 further shows the 2005 Chinese GHG gas emission structure. $\mathrm{CO}_{2}$ was the largest GHG composter, accounting for $90.5 \%$ of total GHG emissions. To reduce $\mathrm{GHG}$ emissions, the $\mathrm{CO}_{2}$ emission target should be met first.

Figure 5. The major $\mathrm{CO}_{2}$-emitting countries from 2002-2008 [10].

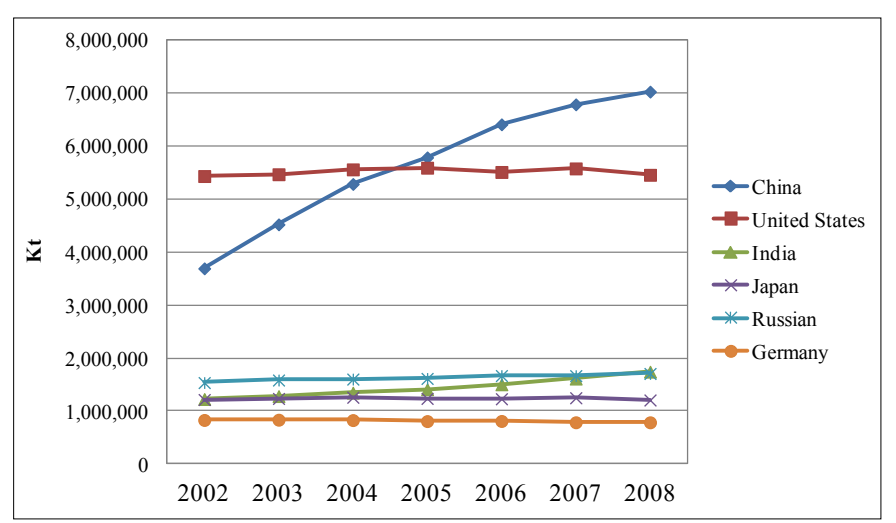

Figure 6. The Chinese greenhouse gas (GHG) emission structure in 2005 [10].

\begin{tabular}{|c|c|c|}
\hline \multirow[t]{2}{*}{$\begin{array}{l}\text { Thousand } \\
\text { metric tons } \\
\text { of } \mathrm{CO}_{2} \\
\text { equivalant }\end{array}$} & $467,213 \longrightarrow{ }^{141,394}$ & $\square \mathrm{CO} 2$ \\
\hline & & $\begin{array}{l}\text { Other greenhouse gas } \\
\text { emissions, HFC, PFC and } \\
\text { SF6 }\end{array}$ \\
\hline
\end{tabular}

As shown in Figure 7, the carbon intensity of China was 313 tons/million CNY, and it has decreased significantly each year from 2005. The carbon intensity was reduced to 224 ton/million CNY in 2010. According to the government plan, the carbon intensity should be reduced by $40 \%-45 \%$ compared with the 2005 level. This reduction would result in a 2020 carbon intensity of 172-188 ton/million CNY. This study is based on the assumptions used to predict the GDP and $\mathrm{CO}_{2}$ emission trends from 2008 to 2010 .

Figure 7. The carbon intensity in China from 2002-2008.

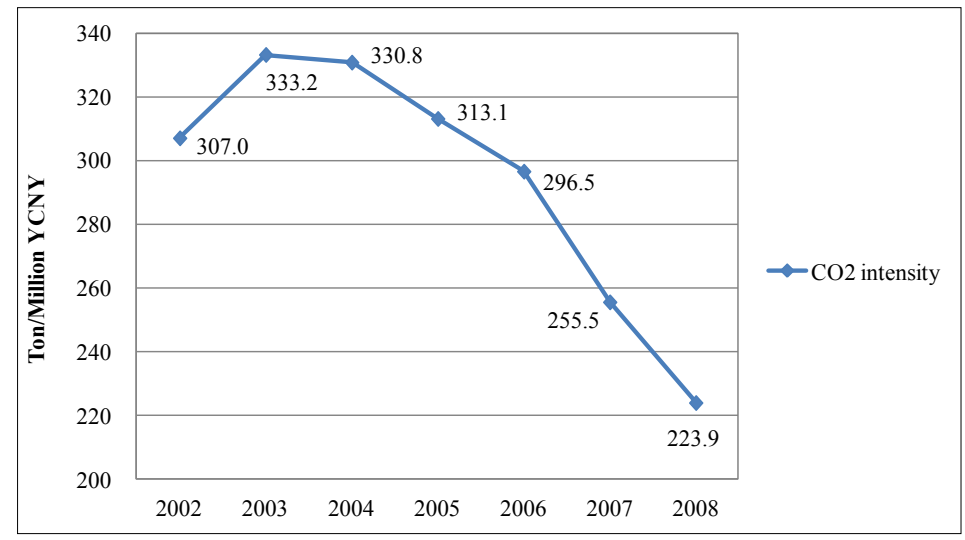


The $\mathrm{CO}_{2}$ emission intensity per GDP $\left(\mathrm{CO}_{2} / \mathrm{GDP}\right)$ is a key indicator of the energy mix, economic efficiency and energy efficiency of one country; the measure has gained much attention from the scientific community and national governments in recent years [11]. Chinese researchers [12,13] all maintain that the per capita accumulated emission is the best way to represent the principle of "common but differentiated responsibility" and the rule of equity and integrity as they pertain to emissions reduction among developed and developing countries. In this study, we also utilized the carbon intensity as the key indicator in our simulation to provide the optimal policy proposals.

\subsection{Research Purposes}

Energy consumption and related $\mathrm{CO}_{2}$ emissions are increasing rapidly to support China's rapid economic development and industrialization. Based on the current situation analysis, we can see that there are several problems in the energy supply, energy consumption, and industry development structures [14,15].

Using policy instruments is essential for achieving the intensity reduction target [16]. However, proposing a suitable government plan for energy and industrial structure adjustment is the most important to effectively achieve the development targets. Various policies exist to pursue these low-carbon society targets, including industrial structural adjustment, by optimizing energy utilization and the $\mathrm{CO}_{2}$ emission structure, implementing technical improvements, enhancing the management, and deepening reform in energy pricing and policies [13].

Among the various approaches to achieving a low-carbon economy, policies concerning energy and industrial structure adjustment are considered to be the most important and efficient $[17,18]$. It is urgent to restructure the primary, secondary and tertiary industries to accelerate service sector development and increase non-energy intensive and low $\mathrm{CO}_{2}$ emitting industries to optimize energy utilization structure and achieve the Chinese government's targets. An industrial and energy structure adjustment cannot only accelerate economic development, but also reduce the carbon intensity. These optimal industrial and energy structure adjustments are essential for national development and are the most important policy-making basis.

This study is based on this consideration and aims to solve the following problems. First, it will determine whether achieving China's $\mathrm{CO}_{2}$ emission and energy structure targets and developing the economy are feasible. Second, it will provide an applicable approach for China to achieve the dual targets of a low-carbon society and socio-economic development given a heightened awareness of balancing economic growth with environment protection. Finally, it will provide a policy-making foundation for future Chinese sustainable development.

This study adopted the dynamic optimization simulation method with the LINGO language programming to precisely reflect the comprehensive socio-economic and environmental systems. This model can simulate the optimal energy supply and demand structure adjustments to maximize the GDP from 2008-2020 under the carbon intensity and $\mathrm{CO}_{2}$ emission limits set by the Chinese government. 


\section{The Methodological Approach}

\subsection{Simulation Methods and Previous Research Results}

There are various studies that estimate China's $\mathrm{CO}_{2}$ emission and energy supply structure trends in the next 10-40 years. Trend extrapolation can indicate whether a country is on course to meet its carbon intensity targets. Among these studies that use various research models and methods, the most illustrative research includes a report published by the Grantham Institute [19] written for the China National Energy Strategy and Policy [20], the International Energy Agency (IEA) [21,22], etc.

In most studies, China's GDP was assumed to maintain a high annual increase rate between 5\% and 8.8\% [23]. The China National Energy Strategy and Policy estimated that, by the end of 2020, China's GDP will quadruple to 36 trillion CNY and the population will be controlled to within 1.5 billion. In the Grantham Institute's Report, the Chinese economy is projected to grow at $8.8 \%$ per annum from 2009-2015 and then at 5.3\% from 2015-2020. Furthermore, it stated that China can achieve a reduction in its carbon intensity of $38 \%$ by 2020 and that further effort would be required to reach the (40\%-45\%) target range. Other studies predicted that China's $\mathrm{CO}_{2}$ emissions will exceed 8 billion [20] or 10 billion tons [21] by the 2020s. Additionally, other simulation methods have been used to predict the economic and energy resource demand trend for China in the next 10 years, such as bottom-up analysis [23] and the LEAP [24], DITS-MEM [25], and MARKAL models [9]. By comparison, the published scenario literature, while technology and policy rich, lacks transparency regarding the many assumptions and model construction foundations.

It is important to forecast $\mathrm{CO}_{2}$ emission to establish the optimal development policies to achieve a low-carbon economy. However, most of the studies and approaches to date provide no insight into the comprehensive socio-economic systems in the simulations. Comprehensive simulation model optimization should be an integrated system in simulation model construction that should consider every factor that will impact the $\mathrm{CO}_{2}$ emission, energy consumption, and industrial development. These factors work and interact with each other to constrain or accelerate their effects on social development. Focusing solely on sector development, regional distribution, or energy structure adjustment cannot precisely simulate a real society's trends and therefore cannot provide convincing and effective solutions to achieve China's targets.

Furthermore, the economic development and energy consumption predictions in these studies under-estimated the development rate in China. For example, the maximum $\mathrm{CO}_{2}$ emission in these studies is only approximately 10 billion tons in 2020, however, the $\mathrm{CO}_{2}$ reached 7032 million tons by 2008 and that trend is apparently increasing. Therefore, to reasonably predict the energy demand and $\mathrm{CO}_{2}$ emissions in the coming years, we need to utilize the latest data for our simulation. This is the only way we can propose the optimal policy guidance for the Chinese government.

This study aims to construct an original comprehensive simulation model to predict the energy and industrial structure and $\mathrm{CO}_{2}$ emission trends based on the latest data and consideration of the comprehensive simulation system. Additionally, detailed information on the model construction, parameters, and assumptions will be given. 


\subsection{Research Method}

This study will first build a comprehensive simulation model system to forecast the $\mathrm{CO}_{2}$ emission based on an input-output table and balances simulating social, economic, and environmental developments. There are three balances in the simulation model: a material flow balance, a value flow balance and an energy flow balance [26]. These simulation models consider many key drivers, such as population growth, GDP growth, energy consumption, and the existing individual sub-sectorial policy targets.

Because the comprehensive simulation model contains many variables and constraints, the dynamic linear programming procedures for solving optimization models are often the most efficient ways to provide a basis for policy-making [27]. The comprehensive simulation model can precisely estimate the impacts that may result from energy structure and $\mathrm{CO}_{2}$ emission decisions. Based on these considerations, this study utilized an optimization simulation model, which is accomplished by dynamic linear LINGO programming, to evaluate the adjustments of energy and industrial structure to achieve carbon intensive reduction targets along with optimized economic development in China.

LINGO (developed by the LINDO Company) is a comprehensive tool designed to make building and solving linear, nonlinear, quadratic, and integer optimization models faster, easier and more efficient. LINGO provides a complete modeling environment to build, solve, and analyze models and includes a powerful language for expressing optimization models, a full featured environment for building and editing problems, and a set of fast built-in solvers [28]. Several studies have utilized this modeling and programming method, and they proved that the method is effective in precisely forecasting socio-economic and environmental development and is reliable and practical to form a basis for policy-making [29]. Therefore, we adopted LINGO to establish the dynamic simulation in our research.

The simulation model is originally constructed based on previous literature and is established by the linear programming method LINGO. We aim to effectively simulate the socio-economic and environmental reality.

\subsection{Simulation Model Concept}

This comprehensive simulation model contains one objective function and three sub-models (an energy flow balance model, a $\mathrm{CO}_{2}$ emission model, and a socio-economic model). The time span of this simulation is from 2008-2020. Data are collected from the China Statistical Yearbook (2008), Input-Output Table of China (2007), energy statistical yearbook of China (2008), etc.

As demonstrated in Figure 8, the objective function maximizes the GDP, and this objective is under carbon intensity limits and industrial input-output constraints. These three sub-models worked together to achieve the optimal economic development under carbon intensity constraints, and reacted with each other to get the suitable development interiorly. The energy flow balance model considers the energy consumption balance, while the energy demand is determined by industrial production. The $\mathrm{CO}_{2}$ emission model reflects the $\mathrm{CO}_{2}$ generation flow from industry, residential consumption, and other forms of energy utilization in society. The socio-economic model is a value flow balance model that includes industrial development, capital changes, imports, etc. The socio-economic model is constructed based on the China input-output table in 2007; industries' development must obey inter-industry constraints provided by the input-output balances. 
Concerning sector classification, this study adopted the traditional three-industry division to compare the national industrial structure changes (shown in Table 1). The energy sector will be specifically introduced as a new integrated sector to specify the energy balance; also, six types of energy resources (coal, natural gas, oil, hydro power, nuclear power, and other new energies) are considered in this simulation to classify the energy consumption trends.

Figure 8. Simulation model framework.

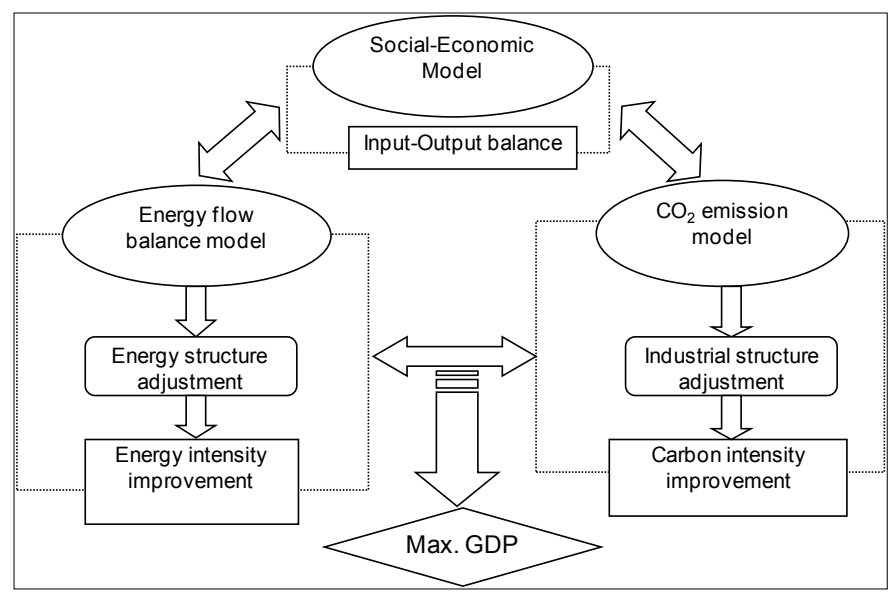

Table 1. Classification of sectors.

\begin{tabular}{ll}
\hline Sectors & Explanation \\
\hline Primary industry & Industries that are involved in raw material development and production \\
\hline Secondary industry & Industries involved in the manufacture of goods \\
\hline Tertiary industry & $\begin{array}{l}\text { Industries that provide transportation or finance rather than } \\
\text { manufacturing or extracting raw materials }\end{array}$ \\
\hline & $\begin{array}{l}\text { The energy sector will be introduced as a new sector that will include } \\
\text { in the simulation all the industries related to the energy production and } \\
\text { consumption in 2008 }\end{array}$ \\
\hline
\end{tabular}

The major constraint of this simulation is carbon intensity; the carbon intensity index upper limit is based on the 2005 carbon intensity. In 2005, the carbon intensity of China was 313 ton/million CNY; it should be reduced to $188-172$ ton/million CNY in 2020 according to the Chinese government plan. Based on this assumption, we set the upper limit of carbon intensity in 2020 as 188 ton/million CNY. Furthermore, the carbon intensity is assumed to decrease yearly from the 2007 level (255.51 ton/million CNY).

Based on the comprehensive evaluation model, this model aims to include most of the important factors that will impact the construction of a low-carbon society. The other factors include population changes, consumption, depreciation, capital changes, etc.

\section{Simulation Modelling Formulation}

In the simulation model, the decision variables can be classified into two types: endogenous (en) and exogenous (ex). The exogenous variables are calculated based on current data, and the values are given in the appendix (some are basic data for parameters' calculation); the endogenous variables will be determined by simulation. The time span ( $t$ ) is 13 years, from 2008-2020. 


\subsection{Objective Function}

The objective of this simulation is to maximize China's GDP; accordingly, the objective function can be formulated as follows:

$$
\begin{gathered}
M A X \sum_{t} G D P(t) \\
G D P(t)=\sum_{n=1}^{4}\left(1-\sum_{m=1}^{4} A_{m n}\right) X_{n}(t)
\end{gathered}
$$

where, $X_{n}(t)$ is the total production from industry $\mathrm{n}(n=1$, Primary industry; $n=2$, Secondary industry; $n=3$, Tertiary industry; $n=4$, Energy industry) (en); $A_{m n}$ is the input-output coefficient matrix (ex).

Because the new energy industry that contains six energy consumption sources will be introduced in this simulation model, the value-added ratio is not stable in each sector; it will change along with the price rate in each year. Therefore, we adopted $\left(1-\sum_{m=1}^{4} A_{m n}\right)$ to demonstrate the value-added ratio and calculate the accurate GDP amount.

\subsection{Energy Flow Balance Model}

The energy demand is determined by normal industry production $\left(X_{n}(t)\right)$ and residential activities. Energy supply comes from six sources: coal, oil, natural gas, hydropower, nuclear energy, and other new energies. The total amount of energy supplies the energy needs for socio-economic activities.

$$
\begin{gathered}
E D T(t)=\sum_{n=1}^{4} E c n \cdot X_{n}(t)+E c r \cdot Z(t) \\
E S T(t)=e c \cdot X_{4}(t)=\sum_{e=1}^{6} E c m \cdot X_{e}(t) \\
E D T(t) \leq E S T(t)
\end{gathered}
$$

$E D T(t)$ is the energy demand or consumption of China at time $\mathrm{t}(\mathrm{en}) ; \operatorname{EST}(t)$ is the energy supply of China at time $t(t)$. Generally, the energy supply must be larger than the energy demand. The energy supply is supported by six energy sources. $X_{e}(t)$ is an energy industry's production at time $\mathrm{t}(e=1$, coal; $e=2$, oil; $e=3$, natural gas; $e=4$, hydro power; $e=5$, nuclear power; $e=6$, other new energy) (en).

$E c n$ and $E c r$ is the energy demand coefficient of the industry $X_{n}(t)$ and population $Z(t)$, respectively (ex); $e c$ is the coefficient of the total energy supply to the energy industry's production $X_{4}(t)$, and $E c m$ is the distinct coefficient of the six types of energy supply sources to their production (ex). The coefficients used in this simulation are calculated based on 2007 data.

\section{3. $\mathrm{CO}_{2}$-Emission Model}

The $\mathrm{CO}_{2}$ emission model demonstrates the $\mathrm{CO}_{2}$ generation ways, including industry's activity, energy supply, and residence consumption.

$$
C O_{2}(t)=\sum_{n=1}^{3} A c n \cdot X_{n}(t)+\sum_{e=1}^{6} A c e \cdot X_{e}(t)+A c r \cdot Z(t)
$$


Where $\mathrm{CO}_{2}(t)$ is the amount of Chinese $\mathrm{CO}_{2}$ emission at time $\mathrm{t}\left(\mathrm{en}\right.$ ); the total $\mathrm{CO}_{2}$ emission is determined by the industry production, six types of energy utilization, and residential consumption at time $\mathrm{t}$.

Acn, Ace, and $\mathrm{Acr}$ are the $\mathrm{CO}_{2}$ emission coefficients of industry production, energy utilization, and population, respectively (ex).

The carbon intensity should be limited to the constraint as follows:

$$
\begin{aligned}
& \mathrm{CO}_{2}(t) / G D P(t) \leq C R \_ \text {upper }(2007) \\
& \mathrm{CO}_{2}(t) / G D P(13) \leq C R \_ \text {lower }(2020)
\end{aligned}
$$

The carbon intensity is defined as $C_{2}(t) / G D P(t)$, and should be less than the upper limit of the carbon intensity in 2007 (255.51 ton/million CNY), and declines each year from 2008-2020. Specifically, the carbon intensity in $2020(t=13)$ should be no larger than 188 ton/million CNY, based on the assumption set previously.

\subsection{Socio-Economic Model}

Equation (9) is the output flow balance equation for the commodity market. The industrial production model is defined based on the input-output constraints:

$$
X_{n}(t) \geq A_{n n} X_{n}(t)+C_{n}(t)+G_{n}(t)+I_{n}(t)+E_{n}(t)-M_{n}(t)
$$

Where $X_{n}(t)$ should obey the output balance between the industries, residential consumption $\left(C_{n}(t)\right.$, en), government consumption $\left(G_{n}(t)\right.$, en), investment $\left(I_{n}(t)\right.$, en), export $\left(E_{n}(t)\right.$, en), and import $\left(M_{n}(t)\right.$, en).

$$
\begin{gathered}
P_{n}(t) \cdot X_{n}(t) \leq P_{n}(t) A_{n n} X_{n}(t)+P_{n}(t) Y_{h n}(t)+P_{n}(t) d_{n}(t)+P_{n}(t) T_{n}(t)+P_{n}(t) S_{n}(t) \\
0.1 \leq P_{n}(t) \leq 10
\end{gathered}
$$

Equation (10) is the input flow balance equation for the commodity market. The industrial production is influenced by the price rate in each year $P_{n}(t)$ (en) (i.e., industry's price fluctuation compared with the initial year). Specifically, the price rate should be limited in the range of 0.1-10, because fluctuation of the price rate will impact on the whole economic development significantly. Each industry's production should be constrained by the inter-relation between the input of industry, compensation of employers $\left(Y_{h n}(t)\right.$,en), depreciation of fixed capital $\left(d_{n}(t)\right.$, en), net taxes on production $\left(T_{n}(t)\right.$, en), and operating surplus $\left(S_{n}(t)\right.$, en).

There are constraints on these indices above; specifically, we will introduce the depreciation of fixed capital $\left(d_{n}(t)\right.$, en)calculation.

$$
\begin{gathered}
d_{n}(t)=d r_{n} \cdot K_{n}(t) \\
X_{n}(t) \leq \alpha_{n} \cdot K_{n}(t) \\
K_{n}(t)=\left(1-d r_{n}\right) \cdot K_{n}(t-1)+I_{n}(t)
\end{gathered}
$$


Where the depreciation of fixed capital $\left(d_{n}(t)\right)$ is the depreciation rate of each industry $\left(d r_{n}\right.$, ex) multiplied by its production; the industry production should also obey the industry capital $\left(K_{n}(t)\right.$, en) constraint and capital-output ratio $\alpha_{n}(\mathrm{en})$. The industry capital is accumulated capital; it contains the industry capital at time $\mathrm{t}$ minus the capital depreciation at time $\mathrm{t}-1$ plus the annual investment at time $\mathrm{t}$.

$$
Z(t+1)=(1+r) \cdot Z(t)
$$

Population $Z(t)$ (en) is calculated based on the previous year's population and the annual population increase rate $\mathrm{r}(r=0.57 \%$, ex $)$. In 2007, the population of China is 1321 million.

These are the socio-economic activities in the simulation. Overall, it is an integrated system for forecasting the $\mathrm{CO}_{2}$ emissions and energy utilization in China and contains various indicators, such as population changes, industry capital and production development, and $\mathrm{CO}_{2}$ emission coefficient.

\section{Simulation Results, Analysis and Discussion}

Established using computer simulation, the forecast total GDP, industrial structure changes, energy supply and demand structure, and carbon intensity trends can be demonstrated according to the simulation results.

\subsection{Carbon Intensity}

Based on the simulation results, China's GDP can steadily increase from 2008-2020 under the constraints of carbon intensity combined with energy structure and industrial structure adjustment as shown in Figure 9. In 2008, the estimated GDP is 26,012 billion CNY, which is lower than the actual value in 2008 ( 31,045 billion CNY), because the 2008 carbon intensity value of the simulation is stricter than reality. However, the GDP increasing rate is higher after 2010 due to the energy and industrial structure adjustment in 2010. Here, we have to mention that the estimated GDP are consistence with the actual GDP from 2008-2010 (3\%-20\% discrepancy), it is applicable to use our simulation results to reflect economic-energy-carbon emission developing trends. In 2020, China's GDP reached 87,404 billion CNY, which is greater than triple the 2008 value. The profound increase in China's GDP is found to be possible under the $\mathrm{CO}_{2}$ emission limitations imposed by simulation. The annual GDP growth rate is $10.27 \%$. While the actual data on the annual GDP growth rate in China are $18 \%, 8 \%$, and $17 \%$ in 2008,2009 , and 2010 , respectively.

Figure 9. China's GDP trend from 2008-2020.

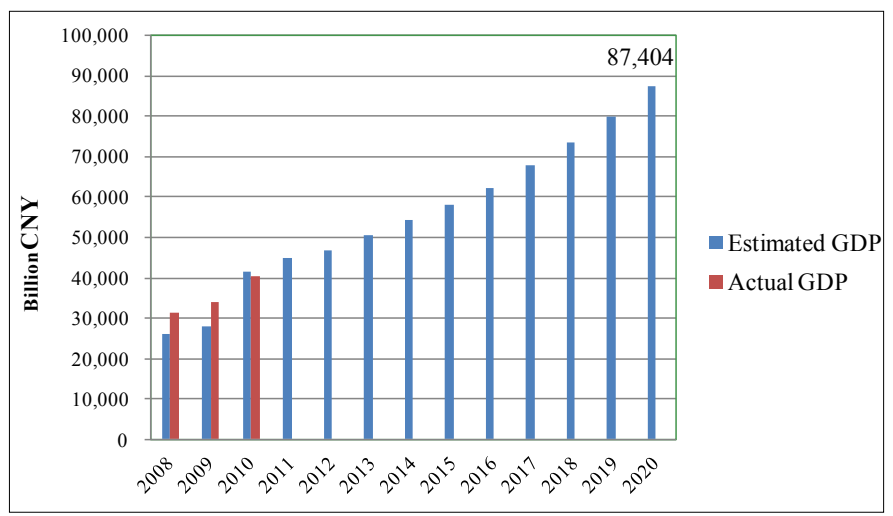


In the simulation, Chinese $\mathrm{CO}_{2}$ emission should increase yearly. Figure 10 shows that the $\mathrm{CO}_{2}$ emission increases from 6.8 billion tons in 2008 to 13.68 billion tons in 2020. The $\mathrm{CO}_{2}$ emission increase rate is $6.04 \%$ in average each year. Large amount of $\mathrm{CO}_{2}$ emission cannot avoided along with high-speed economic development. However, if 13.68 billion tons of $\mathrm{CO}_{2}$ is emitted, it will threaten the whole world environment and climate change. Also, we noticed that this total emission amount is caused by more than $10 \%$ GDP increase rate along with government set energy structure changes by 2020 .

Figure 10. The $\mathrm{CO}_{2}$ emission and carbon intensity trend of China from 2008-2010.

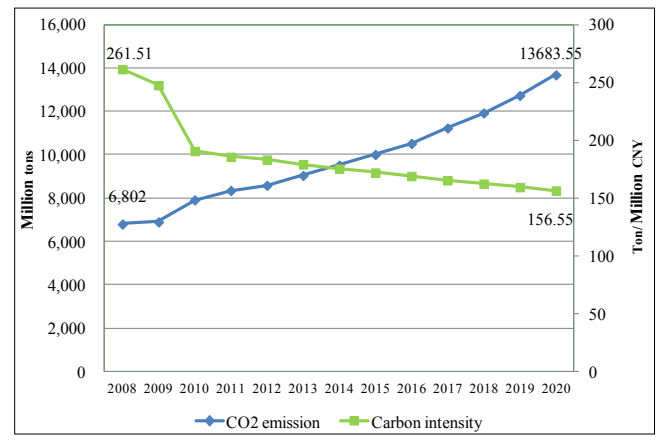

This simulation shows that China can further decrease the carbon intensity by $50 \%$ in 2020 from the 2005 levels; this reduction is even lower than the Chinese government plan (40\%-45\%). Even though the carbon intensity in China can be reduced significantly and continuously by 2020 , the presence of a large $\mathrm{CO}_{2}$ emission cannot be neglected. According to a report of regional $\mathrm{CO}_{2}$ emission reductions for the BLUE Map scenario [30], the baseline global $\mathrm{CO}_{2}$ emissions in 2050 are 57 billion; China's $\mathrm{CO}_{2}$ emission will still be the largest worldwide. China should also pay attention to the total amounts of $\mathrm{CO}_{2}$ emission when pursuing a low-carbon society.

However, the carbon intensity in 2020 calculated in the simulation is less than government targets. Additionally, the Chinese government plan to decrease the carbon intensity to $172-188$ ton/million CNY can be achieved in 2016 according to the simulation. This demonstrates that under the $40 \%-45 \%$ carbon intensity constraint, industrial structure and energy structure adjustment can effectively improve economic development while pursuing a low-carbon society. Even through the carbon intensity target can be achieved according to our simulation, we can see from the results that there are much more potential for China to reduce its carbon intensity and carbon emission.

Reduction by half in the carbon intensity is found to be achievable with a $10.27 \%$ economic annual growth rate from 2008-2020. This implies that, even though it is a large step-forward for China to achieve a low-carbon society, this attempt can be effectively established with the countermeasures we put forward. However, this simulation also implies that perhaps local governments also need a quantitative $\mathrm{CO}_{2}$ emission measurement standard to control the total emission in China and achieve more efficient improvement.

\subsection{Energy Structure Adjustment}

To achieve the dual targets of a low-carbon society and economic development, the energy consumption structure should be changed because it is the major factor impacting the $\mathrm{CO}_{2}$ emission. 
China proposed many approaches to reduce coal consumption because over $70 \%$ of the energy is produced by coal, which has the highest $\mathrm{CO}_{2}$ generation among energy sources. Meanwhile, China also wanted to increase the percentage of energy from non-fossil sources progressively to $15 \%$. Energy is necessary for economic development; industry cannot develop without energy supply.

In this simulation, the non-fossil energies' proportion of energy supply is found to reach as high as $17 \%$ of the total energy supply; this percentage is also higher than the government target (15\%). At the same time, coal's proportion is reduced accordingly. In 2020, the proportions of coal, oil, natural gas, hydropower, nuclear power and other new energies will be $56 \%, 15 \%, 12 \%, 8 \%, 6 \%$, and $3 \%$, respectively.

Energy consumption is influenced by industrial development and the $\mathrm{CO}_{2}$ emission constraints. Along with high economic development, the total energy consumption increases; however, limited by the carbon intensity constraints, clean energy needs to substitute fossil energy gradually to lower each industry's $\mathrm{CO}_{2}$ emission coefficient (as depicted in Figure 11). However, we need to mention that the total amount of energy increased sharply after 2015 due to high economic development. If we can further improve the energy production and utilization technologies after 2015, the carbon emission intensity and energy intensity can be improved further, therefore, there is potential for China to achieve a more efficient low-carbon society. The energy structure adjustment is proved to be effective when achieving low carbon emission and high economic development.

Figure 11. The Chinese energy supply structure trend from 2008-2020.

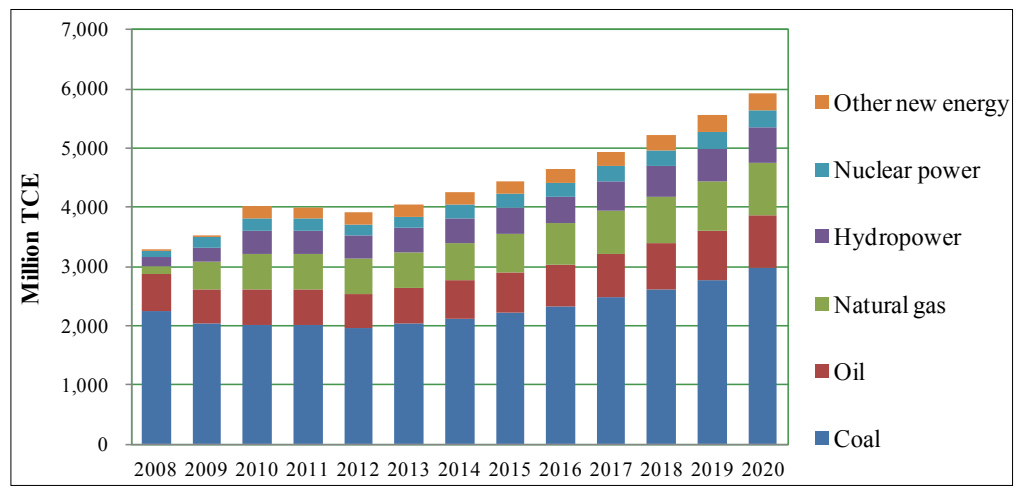

\subsection{Industrial Structure Adjustment}

Figure 12 shows that the total amount of industry production increased significantly from 2008-2020, from 7890 billion CNY to 197,964 billion CNY. There is a huge production increase in China, especially for the tertiary industry.

In 2008, the three industries structure was 12:56:32, and shifts to 4:39:57 in 2020. Industrial structure changes can contribute greatly to the $\mathrm{CO}_{2}$ emission and energy consumption. The tertiary industry has a lower $\mathrm{CO}_{2}$ emission coefficient compared with primary and secondary industry and has a high added value. Therefore, the concentration of industry will shift from the secondary industry to the tertiary industry. The primary industry as the guarantee for necessary living remains stable from 2008-2020.

A large increase of tertiary industry's proportion in China's industrial structure cannot be easily realized as the simulation suggest by 2020 in real society. However, it is essential to prompt service 
sectors' development for low-carbon economy. Furthermore, it is feasible to accelerate the tertiary industry to be the pillar industry in China according to the government plan. Further approaches to accomplish high speed increases of tertiary industry are needed.

Figure 12. The Chinese industrial structure and production trends from 2008-2020.

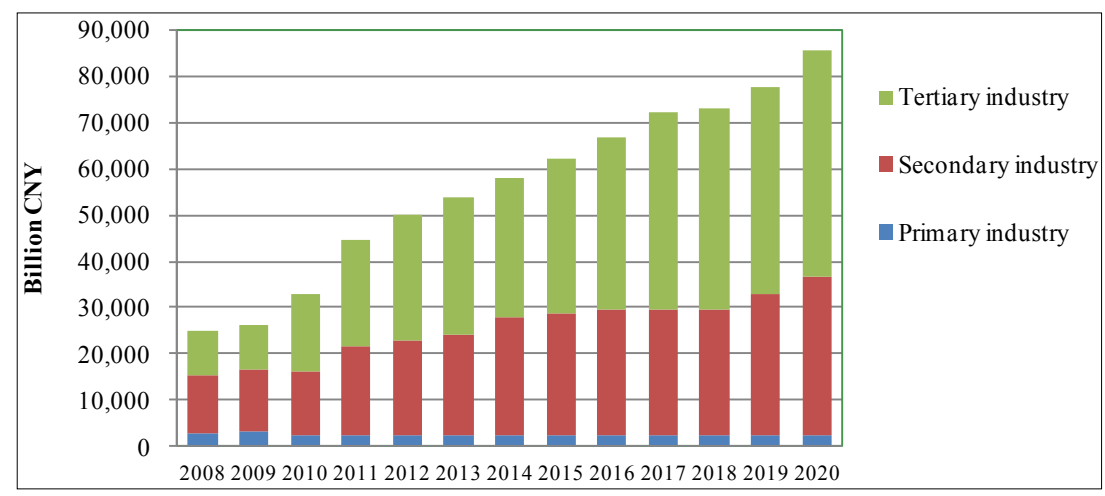

It is necessary to reconstruct the industrial structure not only to limit $\mathrm{CO}_{2}$ emission but also for the life quality improvement in China, which has a high rate of economic development and low life standards; the service-dominant tertiary industry will be essential to China's societal development in the long term.

Although we considered nearly all of the most important factors that impact on $\mathrm{CO}_{2}$ emission and economic development, there are some aspects that still need to be considered in this comprehensive simulation model in the future, such as technology innovation impacts and different kinds of clean energy's influences on $\mathrm{CO}_{2}$ emission and GDP contribution. These call for further improvement of the comprehensive simulation model construction and accomplishment of our research.

\section{Conclusions}

To achieve the reduction target, prioritizing economic development while also emphasizing an environmental development strategy might be successful. The simulation proved that it is necessary to achieve all the targets needed to establish low-carbon economy.

This study elucidated the following points. First, we developed a method for evaluating and estimating a low-carbon society scenario by considering the comprehensive economic and environment system. This method was applied to China from 2008-2020, and the simulation results proved that China could even exceed its low-carbon economy targets when adopting the countermeasures described in this study. China can reduce its carbon intensity by $50 \%$ in 2020 compared to 2005 with $10.27 \%$ per year economic growth.

Second, we utilized this comprehensive simulation method to verify the Chinese low carbon society targets. The carbon intensity can be reduced to 156 ton/million CNY in 2020, or 50\% of that in 2005 . This carbon intensity decrease not only contributes to the $\mathrm{CO}_{2}$ emission constraints but also contributes substantially to energy intensity and efficiency improvement. In this case, China's GDP can also undergo a rapid improvement with an annual development rate of $10.27 \%$. The total GDP will achieve 87,404 billion CNY. Compared with the actual China data from 2008-2010, the simulation results are found to properly reflect the real society. To achieve the controversial GDP increase targets and carbon 
intensity reduction, the energy structure and industrial structure need to be continuously restructured from 2008-2020. In 2020, if the non-fossil energies' proportion reaches $17 \%$ and the industrial structure becomes 7:35:57, China's economy and $\mathrm{CO}_{2}$ emission will achieve the goals established above.

Third, we found out that even though China's carbon intensity targets can be achievable when adjusting energy structure and industrial structure, the total amount of carbon emission will be 13.68 million tons by 2020 along with rapid economic development. China's pursuit of a low-carbon society should not neglect the importance of total emission amount control.

Therefore, this study maintains that energy structure and industrial structure adjustments indeed will be beneficial for low carbon economy; there is still large potential for China to reduce carbon intensity further; if we invest more efforts in technology updates and developing the clean energy supply, China can achieve sustainable development much more effectively. Furthermore, we propose to use the total amount of $\mathrm{CO}_{2}$ emission together with carbon intensity as the targets for the Chinese government.

This comprehensive evaluation model can be used to forecast environmental and economic changes. In this manner, it is possible to achieve not only the $\mathrm{CO}_{2}$ emission targets but also control of the energy and industrial structure to facilitate the development of the economy. The solution proposals provided by simulation can be a practical and an effective basis for policy-making of the Chinese government, and it will provide both a reference and a basis for future national policy-making at various levels to control carbon emission and carbon intensity. This integrated environment policy evaluation and estimation approach can be easily applied to regions with serious environment problems, and it is especially effective for developing countries, which intend to achieve large economic growth in the next few decades. Further research is attempting to propose optimal sustainable development plans for a Chinese low carbon society, as well as air pollution control in North-East China.

\section{Acknowledgments}

This research is supported by grants from the Young Scientists Fund of the National Science Foundation of China (Grant No. 41101559), and the Young Scientists Fund of the Ministry of Education of the People's Republic of China (Grant No. 10YJC790210). The first author gratefully acknowledges the scholarship from the "Construction of High Standard University" program of the China Scholarship Council.

\section{Conflicts of Interest}

The authors declare no conflict of interest.

\section{References}

1. Morrison, W.M. China's economic conditions, CRS Report RL33534. Available online: https://www.opencrs.com/document/RL33534/ (accessed on 14 October 2013).

2. Leggett, J.A.; Logan, J.; Mackey, A. China's greenhouse gas emission and mitigation policies, CRS Report RL34659. Available online: www.fas.org/sgp/crs/row/R41919.pdf (accessed on 14 October 2013). 
3. Levine, M.; Aden, N. Global carbon emissions in the coming decades: The case of China. Annu. Rev. Environ. Resour. 2008, 33, 19-38.

4. World Bank. Cost of Pollution in China: Economic Estimates of Physical Damages; World Bank: Washington, DC, USA, 2007.

5. Grantham Institute for Climate Change. An Assessment of China's 2020 Carbon Intensity Target; Report GR1; Imperial College: London, UK, 2011.

6. Gomi, K.; Shimada, K.; Matsuoka, Y. A low-carbon scenario creation method for a local-scale economy and its application in Kyoto city. Energ. Policy 2010, 38, 4783-4796.

7. Yi, W.J.; Zou, L.L.; Guo, J.; Wang, K.; Wei, Y.M. How can China reach its $\mathrm{CO}_{2}$ intensity reduction targets by 2020? A regional allocation based on equity and development. Energ. Policy 2011, 39, 2407-2415.

8. China Statistics Bureau. China Statistical Yearbook 2007, 2008, 2009, 2010, 2011; China Statistics Press: Beijing, China, 2011.

9. Dolf, G.; Chen, C.H. The $\mathrm{CO}_{2}$ emission reduction benefits of Chinese energy policies and environmental policies: A case study for Shanghai, period 1995-2020. Ecol. Econ. 2001, 39, 257-270.

10. World Bank. Available online: http://www.data.worldbank.org (accessed on 14 October 2013).

11. Chakravarty, A.; Chikkatur, A.; de Coninck, H.; Pacala, S.; Socolow, R.; Mavoni, M. Sharing Global $\mathrm{CO}_{2}$ Emission Reductions among One Billion High Emitters. In Proceedings of the National Academy of Sciences of the United States of America, Fairfax, VA, USA, 6 July 2009.

12. Ding, Z.; Duan, X.; Ge, Q. Control of atmospheric $\mathrm{CO}_{2}$ concentration by 2050: An allocation on the emission rights of different countries. Sci. China Earth Sci. 2009, 39, 1448-1471.

13. Hu, G.; Luo, Y.; Liu, H. Contributions of accumulative per capita emissions to global climate change. Adv. Clim. Chang. Res. 2009, 5, 30-33.

14. Hof, A.; den Elzen, M.G.J.; van Vuuren, D.P. Environmental effectiveness and economic consequences of fragmented vs. universal regimes: What can we learn from model studies. Int. Environ. Agreem. Polit. Law Econ. 2009, 9, 39-62.

15. Jiang, K.J.; Hu, X.L.; Zhuang, X.; Liu, Q.; Zhu, S.L. China's energy demand and greenhouse gas emission scenarios in 2050. Adv. Clim. Chang. Res. 2008, 4, 296-302.

16. Edwards, T.; Hutton, J. Allocation of carbon permits within a country: A general equilibrium analysis of the United Kingdom. Energ. Econ. 2001, 23, 371-386.

17. Tietenberg, T. Economic instruments for environmental regulation. Oxford Rev. Econ. Pol. 1990, $6,17-34$.

18. Viguier, L. Fair trade and harmonization of climate change policies in Europe. Energ. Policy 2001, 21, 749-753.

19. Marland, G. Emissions accounting: China's uncertain $\mathrm{CO}_{2}$ emissions. Nat. Clim. Chang. 2012, 2, 645-646.

20. Xu, H.Q. China National Energy Strategy and Policy 2020-Subtitle 7: Global Climate Change: Challenges, Opportunities, and Strategy Faced by China; Energy Research Institute National Development and Reform Commission: Beijing, China, 2005.

21. International Energy Agency (IEA). World Energy Outlook; IEA/OECD: Paris, France, 2009. 
22. International Energy Agency (IEA). Energy Technology Perspectives 2010; IEA/OECD: Paris, France, 2010.

23. Den Elzen, M.; Höhne, N. Reductions of greenhouse gas emissions in Annex I and non-Annex I countries for meeting concentration stabilisation targets. Clim. Chang. 2008, 91, 249-274.

24. Wang, Y.J.; Gu, A.; Zhang, L. Recent development of energy supply and demand in China, and energy sector prospects through 2030. Energ. Policy 2011, 39, 6745-6759.

25. Lin, Q.G.; Huang, G.H. Planning of energy system management and GHG-emission control in the Municipality of Beijing-An inexact-dynamic stochastic programming model. Energ. Policy 2009, 37, 4463-4473.

26. Higano, Y.; Nijkamp, P.; Poot, J.; Wyk, K.V. The Region in the New Economy: An International Perspective on Regional Dynamics in the 21st Century; Ashgate publishing: Farnham, UK, 2002.

27. Beroggi, G.E.G. Dicision Modelling in Policy Management: An Introduction to Analytic Concepts; Springer: Berlin, Germany, 1999.

28. Li, B.; Higano, Y. An Environmental Socioeconomic Framework Model for Adapting to Climate Change in China. In Globalization and Regional Economic Modeling; Advances in Spatial Science, Part C; Cooper, R., Donaghy, K., Hewings, G., Ed.; Springer: Berlin/Heidelberg, Germany, 2007; pp. 327-349.

29. Xu, F.; Xiang, N.; Higano, Y. Comprehensive Evaluation of Environmental Policies for Sustainable Development in Jiaxing City, China. Environ. Eng. Manag. J. 2013, in press. Available online: http://omicron.ch.tuiasi.ro/EEMJ/accepted.htm (accessed on 14 October 2013).

30. Research Institute of Innovative Technology for the Earth (RITE). Scenario Analysis of Halving Global $\mathrm{CO}_{2}$ Emissions by 2050; RITE: Kyoto, Japan, 2009.

\section{Appendix}

Table A1. Energy production of China from 2006 to 2010.

\begin{tabular}{cccccc}
\hline \multirow{2}{*}{ Year } & $\begin{array}{c}\text { Amount of energy production } \\
\text { (Million TCE) }\end{array}$ & Coal & Oil & Natural gas & Non-fossil energy \\
\cline { 3 - 6 } & $2,321.67$ & 77.8 & 11.3 & 3.4 & 7.5 \\
2006 & $2,472.79$ & 77.7 & 10.8 & 3.7 & 7.8 \\
2007 & $2,605.52$ & 76.8 & 10.5 & 4.09 & 8.62 \\
2008 & $2,746.19$ & 77.3 & 9.9 & 4.1 & 8.7 \\
2009 & $2,969.16$ & 76.5 & 9.8 & 4.3 & 9.4 \\
\hline
\end{tabular}

Table A2. Energy consumption of China from 2006 to 2010.

\begin{tabular}{cccccc}
\hline \multirow{2}{*}{ Year } & $\begin{array}{c}\text { Amount of energy production } \\
\text { (Million TCE) }\end{array}$ & Coal & Oil & Natural gas & Non-fossil energy \\
\hline 2006 & $2,586.76$ & 71.1 & 19.3 & 2.9 & 6.7 \\
2007 & $2,805.08$ & 71.1 & 18.8 & 3.3 & 6.8 \\
2008 & $2,914.48$ & 70.3 & 18.3 & 3.7 & 7.7 \\
2009 & $3,066.47$ & 70.4 & 17.9 & 3.9 & 7.8 \\
2010 & $3,249.39$ & 68 & 19 & 4.4 & 8.6 \\
\hline
\end{tabular}


Table A3. $\mathrm{CO}_{2}$ emissions (Million ton).

\begin{tabular}{cccccccc}
\hline Country & $\mathbf{2 0 0 2}$ & $\mathbf{2 0 0 3}$ & $\mathbf{2 0 0 4}$ & $\mathbf{2 0 0 5}$ & $\mathbf{2 0 0 6}$ & $\mathbf{2 0 0 7}$ & $\mathbf{2 0 0 8}$ \\
\hline China & $36,942.42$ & $45,251.77$ & $52,881.66$ & $57,900.17$ & $64,144.63$ & $67,918.05$ & $70,319.16$ \\
United States & $54,378.16$ & $54,717.54$ & $55,638.00$ & $55,953.58$ & $55,147.76$ & $55,815.37$ & $54,610.14$ \\
India & $12,267.91$ & $12,819.14$ & $13,465.96$ & $14,111.28$ & $15,043.65$ & $16,123.84$ & $17,426.98$ \\
Japan & $12,167.62$ & $12,372.42$ & $12,596.59$ & $12,381.88$ & $12,317.71$ & $12,511.88$ & $12,081.63$ \\
Russian & $15,371.95$ & $15,849.98$ & $16,029.63$ & $16,156.84$ & $16,696.03$ & $16,675.76$ & $17,086.53$ \\
Germany & $8,309.09$ & $8,356.58$ & $8,285.22$ & $8,095.97$ & $8,118.81$ & $7,872.35$ & $7,866.60$ \\
\hline
\end{tabular}

Table A4. Input-Output coefficient A and value-added ratio of four sectors in 2007.

\begin{tabular}{ccccc}
\hline A & Primary & Secondary & Tertiary & Energy \\
\hline Primary & 0.14066 & 0.04572 & 0.01325 & 0.00002 \\
Secondary & 0.20043 & 0.60148 & 0.27195 & 0.28515 \\
Tertiary & 0.06334 & 0.09269 & 0.20133 & 0.08815 \\
Energy & 0.00941 & 0.02990 & 0.01505 & 0.27725 \\
V(value-added ratio) & 0.5862 & 0.2302 & 0.4984 & 0.3494 \\
\hline
\end{tabular}

(C) 2013 by the authors; licensee MDPI, Basel, Switzerland. This article is an open access article distributed under the terms and conditions of the Creative Commons Attribution license (http://creativecommons.org/licenses/by/3.0/). 